\title{
Histological Evidence of Nephroprotective Effect of Ashwagandha (Withania somnifera) Root Extract against Gentamicin Induced Nephrotoxicity in Rats
}

\author{
Sadia Choudhury Shimmi ${ }^{1}$, Nasim Jahan ${ }^{2}$, Nazmul Baqi ${ }^{3}$, Zaida Rahman ${ }^{4}$ \\ Received: June 10, 2013 Accepted: October 31, 2013
}

\begin{abstract}
Background: Kidney damage can occur due to exposure to nephrotoxic drugs, chemicals, toxins and infectious agents, ultimately leading to renal failure, management of which is a great challenge. So, efforts have been focused on traditional and herbal medicines for the treatment of renal failure. Ashwagandha (Withania somnifera) may have free radical scavenging activity and can be used for the prevention and treatment of kidney damage. Objective: To observe the histological evidence of nephroprotective effect of Ashwagandha root against gentamicin induced nephrotoxicity in rats. Materials and Methods: This study was done in the department of Physiology, Sir Salimullah Medical College, Dhaka. A total number of 31 male Wistar albino rats were acclimatized for 14 days. Then, these were divided into two groups, control group consisted of 18 rats (Group A) and Ashwagandha pretreated and gentamicin-treated group consisted of 13 rats (Group B). Control group was again subdivided into baseline control and gentamicin-treated control groups $\left(A_{1}\right.$ and $\left.A_{2}\right)$ - each group contained 9 rats. All the animals received basal diet for 22 consecutive days. In addition to this, animals of Group $A_{2}$ received gentamicin subcutaneously $(100 \mathrm{mg} / \mathrm{kg}$ body weight/day) from $15^{\text {th }}$ to $22^{\text {nd }}$ day and animals of Group B received Ashwagandha root extract $(500 \mathrm{mg} / \mathrm{kg}$ body weight/day orally) for 22 consecutive days and gentamicin subcutaneously $\left(100 \mathrm{mg} / \mathrm{kg}\right.$ body weight/day) from $15^{\text {th }}$ to $22^{\text {nd }}$ day. All the animals were sacrificed on $23^{\text {rd }}$ day. Then kidney samples were collected and histology was done by using standard laboratory procedure. Results: Histological examination of kidney revealed abnormal histological findings in 100\% of gentamicin-treated rats. But $92.31 \%$ of rats in Ashwagandha pretreated and gentamicin-treated group showed almost normal structure and 7.69\% showed mild histological changes. Conclusion: Ashwagandha root may have some nephroprotective effect against gentamicin induced nephrotoxicity.
\end{abstract}

Key words: Nephroprotective, Histology, Ashwagandha, Gentamicin

J Enam Med Col 2014; 4(1): 26-30

\section{Introduction}

The kidney is essential for excreting the metabolic waste products with the formation of urine and also conserves necessary products according to the needs of the body. ${ }^{1}$ Several drugs, toxic xenobiotics or chemicals cause toxic damage of kidney due to its high rate of blood flow (20-25\% of cardiac output). ${ }^{2}$ Metabolites of drugs that are excreted from kidney may have greater toxicity leading to cellular damage. ${ }^{3}$ This nephrotoxicity causes renal hemodynamic impairments. ${ }^{4}$

1. Assistant Professor, Department of Physiology, Delta Medical College, Dhaka

2. Professor, Department of Physiology, Sir Salimullah Medical College, Dhaka

3. MD thesis part student, Department of Pathology, Sir Salimullah Medical College, Dhaka

4. Associate Professor, Department of Pharmacology and Therapeutics, Enam Medical College, Savar, Dhaka

Correspondence Sadia Choudhury Shimmi, E-mail: shimmi_cmc40@yahoo.com 
Gentamicin is a broad spectrum antibiotic belonging to the aminoglycosides group. It is very effective in treating life-threatening gram-negative bacterial and hospital acquired infection. ${ }^{5}$ Among the drugs showing nephrotoxicity, gentamicin is well recognized. It can produce renal tubular necrosis, mainly in the proximal tubule. ${ }^{4}$ This drug causes generation of reactive oxygen species (ROS), which induce cell injury and necrosis via lipid peroxidation. ${ }^{6}$ Signs of nephrotoxicity were found in $17.1 \%$ of patients treated with gentamicin for more than seven days at the dose of $2 \mathrm{mg} / \mathrm{kg}$ body weight 8 hourly. ${ }^{7}$ It has been reported that $55.2 \%$ renal failure occurred with only a single daily dose of 2 to 5 $\mathrm{mg} / \mathrm{kg}$ body weight for seven days. ${ }^{8}$

Withania somnifera, known as Ashwagandha, winter cherry or Indian ginseng, belongs to the family of Solanaceae widely used in the Ayurvedic medicine. ${ }^{9}$ Leaves, fruits, seeds, shoots and roots of this plant have been used traditionally as well. ${ }^{10}$ The roots of Withania somnifera contain 35 chemical constituents. ${ }^{11}$ Withaferin A and withanolides, the active ingredients contribute to the most of the biological actions of Withania. ${ }^{12}$ Roots of this plant are wellknown for their nephroprotective effect. ${ }^{13,14}$ Till today, no side-effects have been found in Ashwagandha. ${ }^{14}$

Renal failure is a continuing challenge with consequence of high morbidity and mortality in our country. Nephroprotective drugs are not available in conventional medicine. In recent years, great effort has been focused on traditional and herbal medicines for the treatment of acute renal failure (ARF). Ashwagandha is reasonably cheap, available and relatively safe. It is cultivated and harvested in some Ayurvedic nurseries of Bangladesh. But there is no documented study about the nephroprotective effect of Ashwagandha in Bangladesh. The present study was designed to observe the histological evidence of nephroprotective role of Ashwagandha in experimental animals after inducing nephrotoxicity by gentamicin.

\section{Materials and Methods}

This study was done in the department of Physiology, Sir Salimullah Medical College (SSMC), Mitford, Dhaka during the period of July 2010 to June 2011.
A total number of 31 apparently healthy Wistar albino male rats, weighing between 150 to 200 grams, aged 90 to 120 days were used. The animals were purchased from animal house of Bangladesh Council of Scientific and Industrial Research (BCSIR), Dhaka. Ethical permission was taken from the Institutional Ethics Committee (IEC) of SSMC, Dhaka. Before conducting the study, the animals were acclimatized for 14 days at $23 \pm 2^{0} \mathrm{C}$ room temperature under 12-hour dark-light cycle. During this period, they had free access to food and water ad libitum.

Roots of Ashwagandha were collected from the Ayurvedic nursery of Hamdard Laboratories, Meghna, Dhaka; these were dried in sunlight for 2 days, crushed in an electrical grinder into powder. Then the powder was extracted in methanol, filtered, evaporated by rotatory evaporator and dried. Then the dried root extract of Ashwagandha $(500 \mathrm{mg} / \mathrm{kg}$ body weight/day) was dissolved in propylene glycol (2 $\mathrm{mL} / \mathrm{kg}$ body weight) and finally mixed with distilled water for feeding.

The animals were divided into two groups - control group (Group A) consisted of 18 rats and Ashwagandha pretreated and gentamicin-treated group (Group B) consisted of 13 rats. Control group was again subdivided into Group $\mathrm{A}_{1}$ (baseline control group) and Group $A_{2}$ (gentamicin-treated control group) - each of these groups contained 9 rats. Animals of all groups of received basal diet for 22 consecutive days. Group $\mathrm{A}_{2}$ also received gentamicin subcutaneously ( $100 \mathrm{mg} / \mathrm{kg}$ body weight/day) for the last eight $\left(15^{\text {th }}\right.$ to $\left.22^{\text {nd }}\right)$ consecutive days. Animals of Group B received Ashwagandha root extract (500 $\mathrm{mg} / \mathrm{kg}$ body weight/day orally) in the morning before giving food for 22 consecutive days and gentamicin subcutaneously (100 mg/kg body weight/day) for last eight $\left(15^{\text {th }}\right.$ to $\left.22^{\text {nd }}\right)$ days. On the $23^{\text {rd }}$ day all the animals were anesthetized with the help of chloroform and sacrificed. Then kidney samples were collected and washed in ice-cold saline water. Then, these were wiped with tissue paper and weighed by electric balance analyzer. Histopathology of kidney was also done by using standard laboratory procedure in the department of Pathology, SSMC. Statistical analyses were done by Bonferroni test by using SPSS windows version 16.0. 


\section{Results}

Table I shows the mean kidney weight of different groups of rats and also the comparison of mean weights between groups. The kidney weight was significantly higher $(\mathrm{p}<0.01)$ in Group $\mathrm{A}_{2}$ compared to that of Group $A_{1}$ and Group B. In Group B it was found higher compared to Group $A_{1}$, but the difference was not statistically significant.

Table I: Comparison of net weight of kidneys between groups

\begin{tabular}{|l|c|l|}
\hline Groups & Weight & P value \\
\hline $\mathrm{A}_{1}$ vs $\mathrm{A}_{2}$ & $0.57 \pm 0.03 \mathrm{~g}$ and $1.2 \pm 0.14 \mathrm{~g}$ & $0.001^{* *}$ \\
$\mathrm{~A}_{1}$ vs $\mathrm{B}$ & $0.57 \pm 0.03 \mathrm{~g}$ and $0.58 \pm 0.01 \mathrm{~g}$ & $0.405^{\mathrm{ns}}$ \\
$\mathrm{A}_{2}$ vs $\mathrm{B}$ & $1.2 \pm 0.14 \mathrm{~g}$ and $0.58 \pm 0.01 \mathrm{~g}$ & $0.003^{* *}$
\end{tabular}

Statistical analysis was done by Bonferroni test.

Group $\mathrm{A}_{1}$, Baseline control group; Group $\mathrm{A}_{2}$, Gentamicintreated control group; Group B, Ashwagandha pretreated and gentamicin-treated group

$\mathrm{ns}$, nonsignificant; ${ }^{* *}$, significant at $\mathrm{p}<0.01$

Histological examination of kidneys revealed normal findings (Fig 1) in $100 \%$ of rats in Group $A_{1}$, whereas moderate histological changes such as glomerular hypercellularity (Fig 2), presence of tubular necrosis and loss of lining epithelium of tubules (Fig 3 ), infiltration of lymphocytes (Fig 4), hyaline cast in the tubules (Fig 5) were observed in $100 \%$ of rats in Group $\mathrm{A}_{2}$. In Group B $92.31 \%$ of rats showed almost normal structure (Fig 6) and 7.69\% of them showed mild histological changes in kidney. Table II shows the distribution of different groups of rats by histological changes.

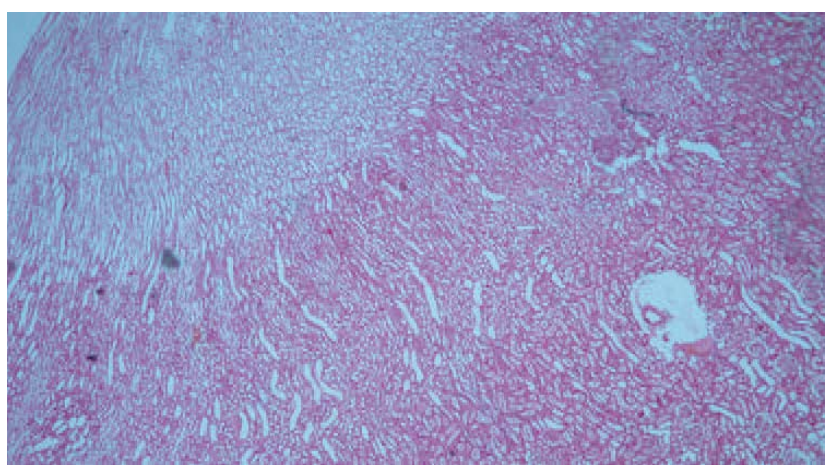

Fig 1. Photomicrograph showing architecture of kidney of baseline control rats $(\times 100)$

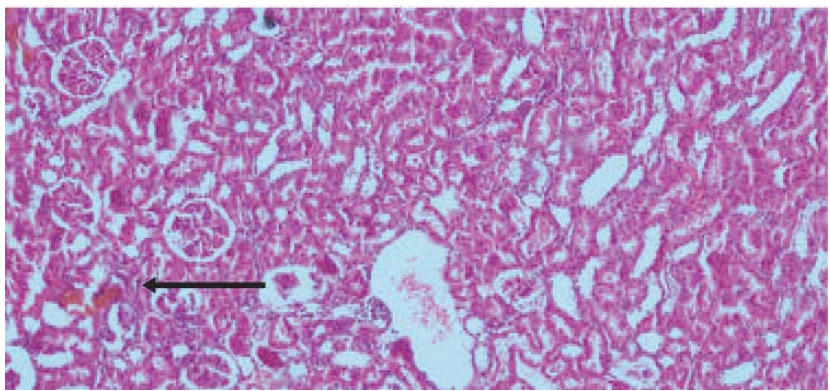

Fig 2. Photomicrograph showing glomerular hypercellularity (arrow mark) of kidney of gentamicin-treated control rats $(\times 400)$

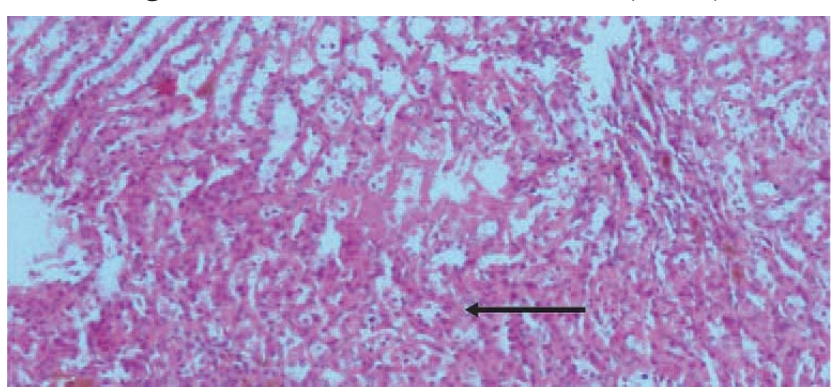

Fig 3. Photomicrograph showing tubular necrosis and loss of lining epithelium (arrow mark) of kidney of gentamicin-treated control rats $(\times 400)$

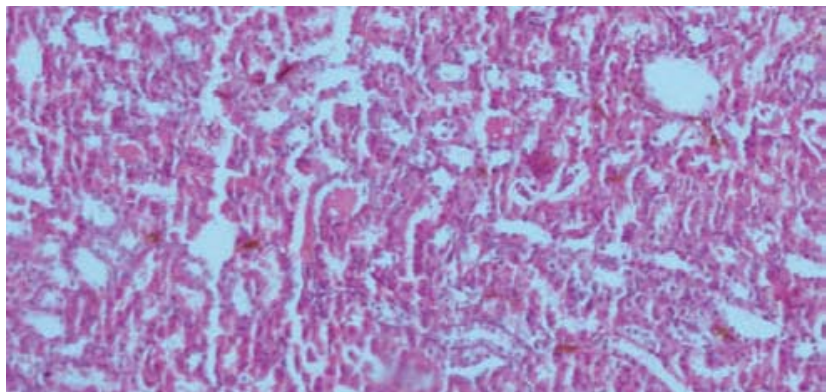

Fig 4. Photomicrograph showing hyaline cast in tubules of kidney of gentamicin-treated control rats $(\times 400)$

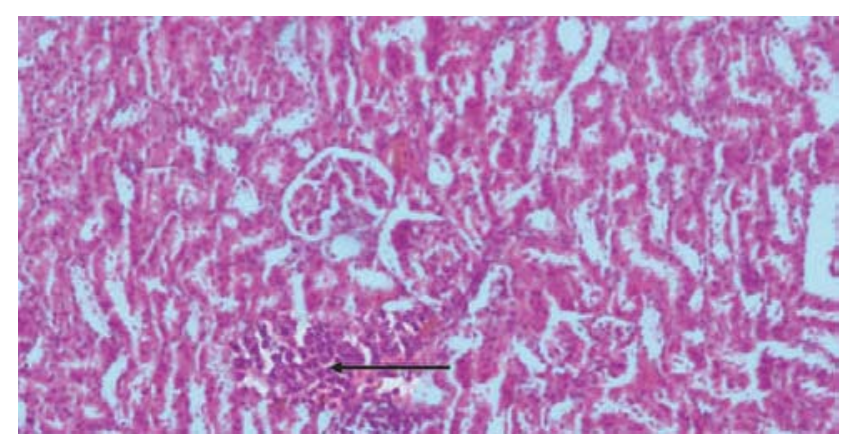

Fig 5. Photomicrograph showing lymphocytic infiltration in tubules (arrow mark) of kidney of gentamicin-treated control rats $(\times 400)$ 


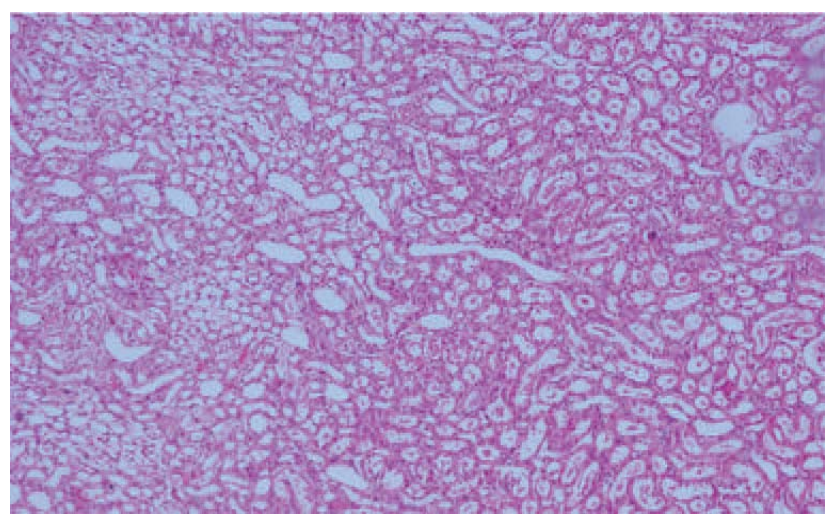

Fig 6. Photomicrograph showing improvement of glomerular and renal tubular changes of kidney in Ashwagandha pretreated and gentamicin-treated rats $(\times 100)$

Table II: Distribution of different groups of rats by histological changes in kidney $(n=31)$

\begin{tabular}{|c|c|c|}
\hline Groups & \multicolumn{2}{|c|}{ Histological findings } \\
& $\begin{array}{c}\text { Normal } \\
\text { Number (\%) }\end{array}$ & $\begin{array}{c}\text { Abnormal } \\
\text { Number (\%) }\end{array}$ \\
\hline $\mathrm{A}_{1}(\mathrm{n}=9)$ & $9(100.00)$ & $0(0.00)$ \\
$\mathrm{A}_{2}(\mathrm{n}=9)$ & $0(0.00)$ & $9(100.00)$ \\
$\mathrm{B}(\mathrm{n}=13)$ & $12(92.31)$ & $1(7.69)$ \\
\hline
\end{tabular}

\section{Discussion}

In this study, the kidney weight was significantly $(\mathrm{p}<0.01)$ higher in gentamicin-treated control rats compared to that of baseline control group and Ashwagandha pretreated and gentamicin-treated group; but no significant difference was observed between baseline control group and Ashwagandha pretreated and gentamicin-treated group. This finding is in consistence with that of some other investigators. ${ }^{13,15}$

Moderate histological changes such as glomerular hypercellularity, tubular necrosis, loss of lining epithelium of tubules, infiltration of lymphocytes and hyaline cast in the tubules were observed in this study in gentamicin-treated control group. These findings are also in agreement with those of different investigators of other countries. ${ }^{6,15,16}$ In Ashwagandha pretreated and gentamicin-treated group $92.31 \%$ of rats showed almost normal kidney architecture and only minimal histological changes of kidney were noted in $7.69 \%$ rats. Some investigators ${ }^{13}$ observed the similar types of findings.

Gentamicin-induced toxicity causes edema and inflammatory changes in the proximal tubular epithelial cells and thereby increases the kidney weight. ${ }^{13}$

Gentamicin-treated animals showed glomerular hypercellularity, tubular necrosis, loss of lining epithelium of tubules, infiltration of lymphocytes and hyaline cast in the tubules in toxic dose. It may be due to increased production of free radicals. ${ }^{6,15,16}$ It has also been suggested that gentamicin causes alteration at the basolateral membrane and mitochondria, and enhances generation of free radicals and lipid peroxidation in renal cortex. ${ }^{17,18}$

The active principles of Ashwagandha, sitoindosides VII-X and withaferin A, have antioxidant activity by enhancing the free radical scavenging enzymes such as superoxide dismutase (SOD), catalase (CAT), glutathione peroxidase (GPx). ${ }^{9}, 12$ So, it may improve the histological architecture of kidney. ${ }^{13,14}$

It has been suggested that Ashwagandha root extract contains withanolides which inhibit cyclooxygenase enzymes, lipid peroxidation and proliferation of tumor cells. Thus, it preferentially reduces inflammatory process by inactivating nuclear factor kappa B (NF-KB) activation. This anti-inflammatory property may be helpful in protecting the kidney from damage. ${ }^{19}$

In the present study, nephrotoxicity was observed in rats treated with gentamicin as evidenced by moderate histological changes of kidneys. This is further supported by an increase in kidney weight in gentamicin-treated rats. It may be due to increased production of free radicals which initiate lipid peroxidation and subsequent cellular damage.

Again, restoration of architecture of glomerulus and renal tubules in Ashwagandha pretreated and gentamicin-treated group provides a direct evidence of nephroprotective effect of this root extract. Furthermore, decrease in kidney weight in this group of rats of the present study suggested the nephroprotective role of this root extract against gentamicin toxicity. These effects are most likely due 
to free radical scavenging activity of Ashwagandha. However, the exact mechanism involved in the nephroprotective activity of Ashwagandha root extract against gentamicin induced nephrotoxicity in rats could not be found out from this study.

\section{References}

1. Urine formation by the kidneys: I. Glomerular filtration, renal blood flow, and their control. In: Hall JE (ed). Guyton and Hall text book of medical physiology. $12^{\text {th }}$ edn. Philadelphia: Saunders Elsevier, 2011: 303-322.

2. Pfaller W, Gstraunthaler G. Nephrotoxicity testing in vitro - what we know and what we need to know. Environ Health Perspect 1998; 106(2): 559-569.

3. Meena MK, Kushwah HK, Rajagopala M, Ravishankar B. An experimental evaluation on nephroprotective activity of Nagaradi kashaya. AYU 2009; 30(1): 55-61.

4. Stojiljkovic N, Veljkovic S, Mihailovic D, Stoiljkovic M, Radovanovic D, Randelovic P. The effect of calcium channel blocker verapamil on gentamicin nephrotoxicity in rats. Bosn J Basic Med Sci 2008; 8(2): 170-176.

5. Raheem ITA, Sherbiny GAE, Taye A. Green tea ameliorates renal oxidative damage induced by gentamicin in rats. Pak J Pharm Sci 2010; 23(1): 21-28.

6. Mahesh CM, Gowda KP, Gupta AK. Protective action of Cuminum cyminum against gentamicin induced nephrotoxicity. JPR 2010; 3(4): 753-757.

7. Smith CR, Lietman PS. Effect of furosemide on aminoglycoside induced nephrotoxicity and auditory toxicity in humans. Antimicrob Agents Chemother 1983; 23(1): 133-137.

8. Kumin GD. Clinical nephrotoxicity of tobramicin and gentamicin: a prospective study. J Am Med Assoc 1980; 244(16): 1808-1810.

9. Mishra LC. Scientific Basis for the therapeutic use of Withania somnifera (Ashwagandha): a review. Altern Med Re 2000; 5(4): 334-346.
10. Widodo N, Kaur K, Shrestha BG, Takagi Y, Ishii T, Renu $\mathrm{W}$ et al. Selective killing of cancer cells by leaf extract of Ashwagandha: identification of a tumor inhibitory factor and the first molecular insights to its effect. Clin Cancer Res 2007; 13(7): 2298-2306.

11. Rastogi RP, Mehrotra BN. Compendium of Indian medicinal plants. Central Drug Research Institute; 1998. No. 5: $16-18$

12. Singh G, Sharma PK, Singh S. Biological activities of Withania somnifera. Annals of Biological Research 2010; 1(3): 56-63.

13. Jeyanthi T, Subramanian P. Nephroprotective effect of Withania somnifera: a dose-dependent study. Renal Failure 2009; 31(9): 814-821.

14. Das K, Samanta TT, Samanta P, Nandi DK. Effect of extract of Withania somnifera on dehydration-induced oxidative stress-related uremia in male rats. Saudi J of Kidney Dis Transpl 2010; 21(1): 75-80.

15. Lakshmi BVS, Sudhakar M. Protective effect of Zingiber officinale on gentamicin-induced nephrotoxicity in rats. Int J Pharmacol 2010; 6(1): 58-62.

16. Zahid M, Kamal F, Qamar MZ, Bhatti SA, Insari NI. Morphological changes produced by aminoglycoside induced nephrotoxicity - an experimental study. Annals 2007; 13(4): 234-237.

17. Soni M, Patidar K, Jain S, Jain D. Nephrotoxins: the main culprit of nephrotoxic injury. Drug Invention Today 2010; 2(2): 173-177.

18. Hozayen W, Bastawy M, Elshafeey H. Effect of Acqueous Purslane (Portulaca oleracea) extract and fish oil on gentamicin nephrotoxicity in albino rats. Nature and Science 2011; 9(2): 47-62.

19. Ichikawa H, Takada Y, Shishodia S, Jayaprakasham B, Nair MG, Aggarwal BB. Withanolides potentiate apoptosis, inhibits invasion and abolish osteoclastogenesis through suppression of nuclear factor-kappa B (NF-KB) activation and NF-kappa B-regulated gene expression. Mol Cancer Ther 2006; 5(6): 1434-1445. 